

\title{
Los objetos inquietos en el hogar español durante el franquismo a través de las revistas de decoración
}

\author{
The restless objects in the Spanish home during the Franco Era through \\ interior design and decoration magazines
}

Dra. Ana María Fernández García*

Resumen

El objetivo de este trabajo es ofrecer una visión de conjunto de las principales publicaciones periódicas dedicadas al diseño de interiores y la decoración en España durante el franquismo (1939-1975), analizando los principales títulos, su público, secciones y principales contenidos. En esas publicaciones se condensa el cambio de los interiores domésticos de este periodo, desde un modelo de amueblamiento autárquico, con productos nacionales, hasta el aperturismo del consumo en el segundo periodo del régimen fascista. El trabajo se ha realizado partiendo del análisis de las principales publicaciones, identificando a sus promotores y desarrollando en discurso de interiorismo que correspondía a cada momento histórico.

\section{Palabras clave}

España; Revistas de decoración; Franquismo; Decoración de interiores.

\begin{abstract}
The objective of this article is to offer an overview of the main journals devoted to interior design and decoration in Spain during the years of Franco's regime (1939-1975), analyzing the main works, their audience, sections and contents. In these publications, the change of the domestic interiors of this period is condensed, from an authocratic furnishing model, with national products, to the launching of consumption in the second period of the fascist regime. In this research we will highlight two main types of publications: a professional one, related to architects and written by experts in this field, and a more general one, directed to the female public, and related to the role of women in terms of decorating their homes. This work has been carried out focusing on the analysis of the main publications, identifying their promoters and analyzing the type of interior design corresponding to each historical moment.
\end{abstract}

\section{Keywords}

Spain; Decoration Journals; Franco's Regime; Interior Design. 
Después del alzamiento militar de las tropas lideradas por el general Franco y de la cruenta Guerra Civil (1936-1939), la dictadura militar de Francisco Franco, hasta su muerte en 1975, no sólo supuso en periodo político, social y económico que marcó la historia de España, sino que incluso en el análisis de consumo de objetos suntuarios, en modas decorativas y en políticas editoriales, podemos rastrear singularidades nacionales con respecto a otros escenarios geográficos. En la secuencia cronológica de revistas dedicadas a la decoración de interiores podemos distinguir dos periodos que coinciden no de forma casual con las etapas del Régimen de Franco en España y que sólo se explican por las circunstancias históricas derivadas de la cultura fascista.

En un primer momento, que coindice con la fase autárquica (1939-1959), fue un periodo de aislamiento internacional (especialmente a partir de la derrota del bloque fascista alemán e italiano), de represión, pero también de muchas dificultades económicas ${ }^{1}$, estando el escenario de las revistas dedicadas a la decoración de interiores centrado en editoriales de Madrid. Las principales revistas estaban dirigidas por arquitectos, generalmente próximos a la Falange ${ }^{2}$, y eran publicaciones de carácter heterodoxo, donde convivían los artículos de arquitectos, con recomendaciones decorativas para el hogar, críticas de arte o literarias, y donde el aparato publicitario era reducido. En algunos casos, como sucedía con la revista Hogar y Arquitectura (fundada en 1955), estaban incardinadas en las instituciones del Régimen, en este caso con la Obra Sindical del Hogar y la Arquitectura. Por eso no resulta extraño que insistiesen reiterativamente en el hogar como reducto de la familia cristiana y en los estilos históricos y "nacionales" como recurso decorativo.

En un segundo momento, que coincide con el tardofranquismo (1960-1975) o periodo tecnócrata, el país experimentó un despegue económico alimentado por el turismo extranjero y por el aperturismo político que finalizaba el aislamiento del régimen (en la época de los pactos con el gobierno de Estados Unidos). Hay una progresiva liberación económica, comienzan las importaciones y también se produce una cierta liberación de las costumbres. En esos años de mejora económico y cultural, el escenario de las revistas especializadas de decoración cambió radicalmente. Se aproximan más a lo que actualmente entendemos como publicaciones especializadas: abundancia de color, anuncios publicitarios, empleo de recursos de marketing moderno... además el foco editorial se trasladó a Barcelona, donde se publicarían las mejores y más exitosas revistas, de la mano de una floreciente industria del mueble en Cataluña. Eran publicaciones con mucho aparato fotográfico y expondrían las novedades de la decoración internacional. Se suprimieron los discursos ideológicos a favor de mensajes relacionados con lo "moderno", lo "práctico" y lo "útil". Los articulistas serán ya decoradores o periodistas, y la organización de cada número se hará en secciones fijas adaptadas a las demandas del público.

\section{La revista de decoración de la postguerra. Arte y Hogar}

La publicación que mejor resume las características de las revistas dedicadas a la decoración durante la Autarquía es Arte y Hogar [fig. 1]. El primer número de esta revista, editada por Ediciones Cigüeña, propiedad de Fermina Bonilla, vio la luz en diciembre de 1943. La revista Arte y Hogar no era una publicación de interiorismo tal como la entendemos hoy sino que un híbrido entre la edición periódica de temas culturales (había por ejemplo secciones de crítica de música, de arte o de libros), la revista especializada de arquitectura (dado que se incluían ejemplos de edificios con explicación del autor), y 
la orientación al ama de casa pues se incluían todo tipo de consejos del hogar, belleza y moda, con los artículos dedicados de manera específica a la decoración de interiores.

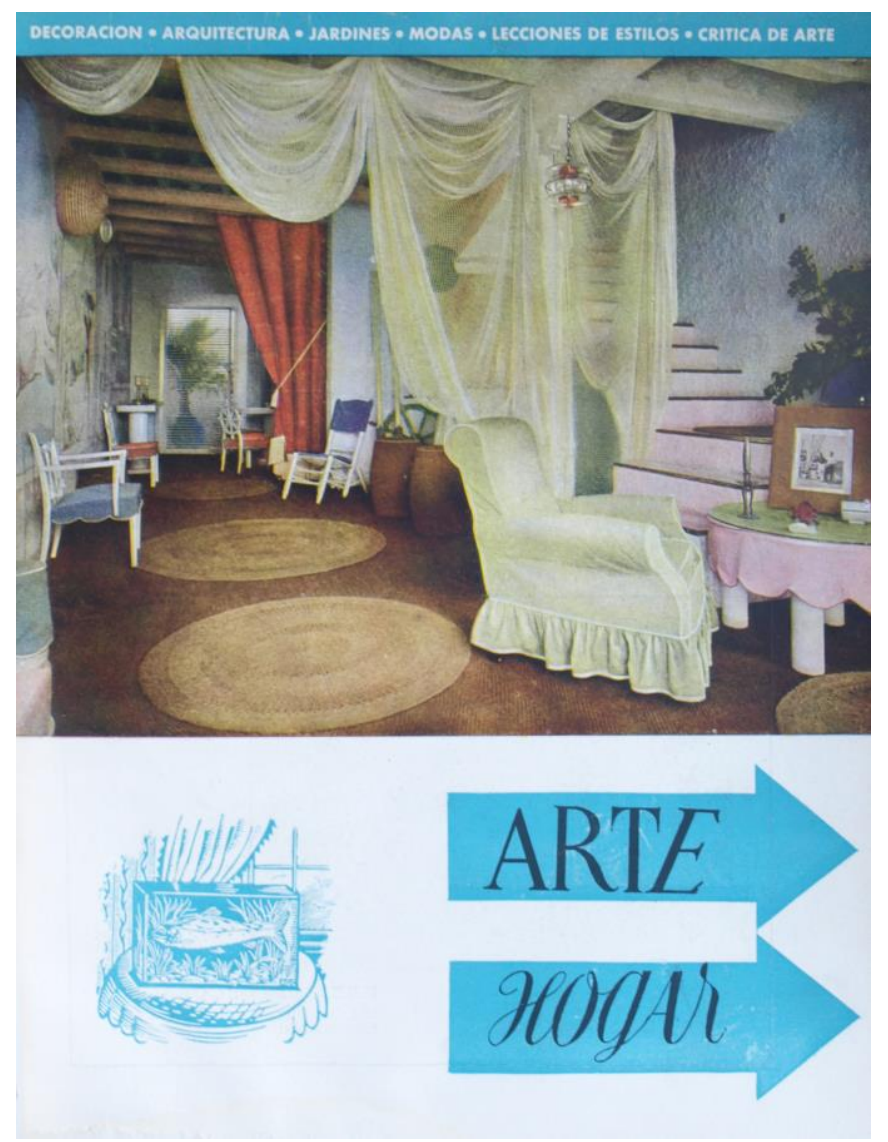

Fig. 1. La revista Arte y Hogar. Arquivo da autora.

Esta fue la primera revista con páginas en color dedicada a la decoración y al arte, con la voluntad (como se recogía en la presentación del primer número) de orientarse a "los sutiles temas del arte, de la decoración, de los estilos, del mobiliario, del montaje del hogar, de la puesta en marcha de la casa... con un sentido positivo y práctico". Como muchas revistas de la postguerra, en la misma presentación se recordaba al Caudillo Francisco Franco porque "al extirpar de nuestro suelo doctrinas bárbaramente extrañas, nos dio de nuevo familia y hogar para que dentro de su seno hiciésemos grande a la Patria" (Presentación, 1943: 6).

Tampoco los promotores de esta iniciativa eran convencionales. La dirección correspondía al arquitecto Eduardo Olasagasti Irigoyen (1909-1975) un profesional muy próximo al Régimen franquista, que había trabajado en regiones devastadas, había proyectado el monumento a los 
Caídos de la División Azul en 1940 (Astorga, 2006: 285-314), había diseñado la Casa del Partido junto a Manuel Ambrós y además estuvo muy vinculado con el departamento técnico de la Obra Sindical del Hogar y la Arquitectura (OSH)3. Para la OSH, Eduardo Olasagasti, junto a Gamir y Álvarez de Sotomayor, proyectaría el Grupo Nuestra Señora del Pilar en Madrid con más de 1200 viviendas en 1945. Por su parte, la dirección artística de Arte y Hogar correspondía a Domingo Viladomat Pancorbo (1912-1994), un artista madrileño formado en la Academia de Bellas Artes de San Fernando, que además de sus trabajos como ilustrador ${ }^{4}$, desarrolló una carrera polifacética como director de cine ${ }^{5}$, escenógrafo y pintor de caballete.

Aunque la orientación ideológica de sus directores era claramente franquista, en realidad la revista era bastante aséptica a nivel político y muy variada en contenidos. Los colaboradores eran profesionales de primer nivel en el país, como el Marqués de Lozoya (Director General de Bellas Artes entonces) para temas históricos, arquitectos que exponían un proyecto determinado - con nombres tan conocidos como Fernando Chueca, Aburto, Cordech o Echenique -, modistos como Balenciaga, el crítico de arte Benito Rodríguez Filloy 6 , el que fuera director de El Museo Romántico de Madrid, Mariano Rodríguez de Rivas, o el poeta, guionista y periodista Federico Muelas.

Paralelamente a ese elenco de colaboradores de tanto prestigio, la publicación también se nutría de mujeres. El caso más relevante desde nuestro punto de vista fue el de Nellie Younger, viuda del capitán de regulares Manuel Manso de Zúñiga, una inglesa que nunca firmaba con sus apellidos de soltera pues hay que tener en cuenta que los ingleses estaban en el bloque aliado y el régimen de Franco apoyó al bloque fascista. Por eso utilizaba los apellidos de su marido fallecido, un militar conocido de la guerra civil ${ }^{7}$. Era ella la que se ocupaba del llamado "Consultorio de decoración", donde se asesoraba sobre problemas de interiorismo de los lectores, con una explicación gráfica de las soluciones propuestas. Otro de los colaboradores era Víctor María Cortezo (1908-1978) - "Vitín" -, dibujante, figurinista teatral, poeta aficionado y republicano, amigo de Luis Cernuda y que terminaría la Guerra Civil en un campo de prisioneros a las afueras de Madrid ${ }^{8}$. De allí fue reclamado por Luis Escobar, que era Director del Teatro Nacional de la Falange, para hacer los decorados y figurines de las representaciones teatrales. En la revista, Cortezo se encargaría de diversas ilustraciones y artículos relacionados con la decoración histórica, recreando interiores de palacios madrileños.

En cuanto a los contenidos de la revista hay que advertir que excepto la portada y la contraportada y dos páginas del interior, el contenido era mayoritariamente en blanco y negro. Incluía una reducidísima publicidad de casas comerciales de muebles y objetos domésticos (siempre producidos en España), pero también artículos de cosmética femenina, lo que refuerza la idea de que uno de sus destinatarios potenciales eran las amas de casa, junto a los técnicos y arquitectos que igualmente exponían sus proyectos en las páginas de la publicación.

Había algunas secciones fijas, como el consultorio del hogar (sección firmada bajo el nombre de Mary Ann pero que hasta el momento no ha sido posible identificar), el consultorio de decoración de Nellie, el apartado de moda, las lecciones de estilo escritas por el Marqués de Lozoya, que 
repasaban los principales estilos históricos españoles, resúmenes ilustrados de visitas realizadas a viviendas aristócratas y otro apartado dedicado a la exposición de proyectos de viviendas a cargo de distintos arquitectos. En la escasa publicidad de cada número se daba difusión a las casas comerciales de decoración instaladas en Madrid (como Loscertales o Rolaco) y había invariablemente unas páginas concentradas en objetos y artesanía típicamente españolas. El contenido era veladamente una exaltación de la historia del país, de sus singularidades, en una concepción muy propia de un Régimen como el de Franco (que por otra parte tenía un férreo control de la información a través de la censura) que validaba el presente con la legitimación de la historia.

\section{Revista El Mueble. La primera revista moderna sobre decoración}

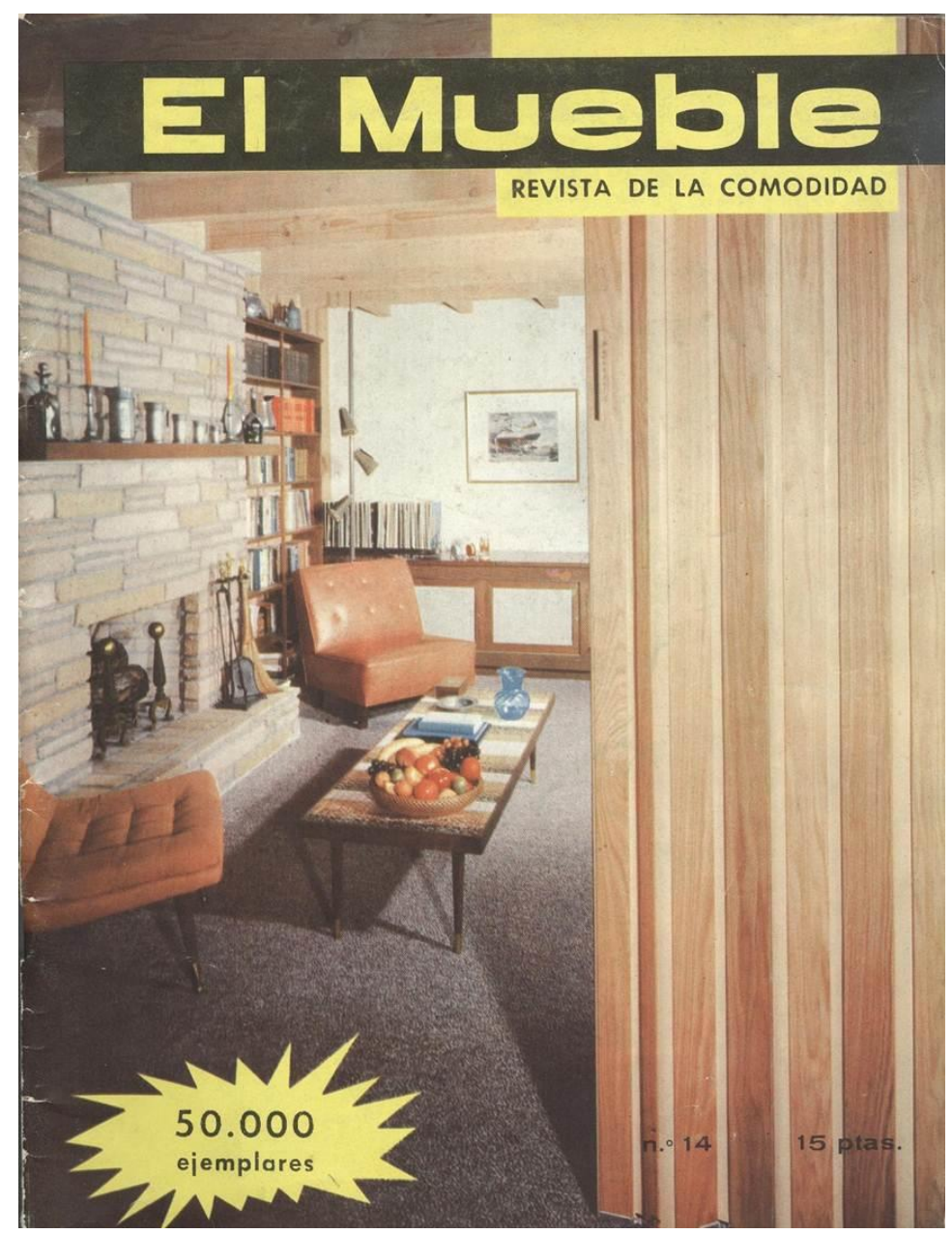

Fig. 2. La revista El Mueble. Arquivo da autora.

Como publicación que ejemplifica los cambios en las revistas de decoración españolas durante el periodo aperturista se ha seleccionado El Mueble [fig. 2], fundada en enero de 1961 y que aún hoy continúa en los kioscos, aunque en 1991 sería adquirida por el Grupo RBA. El fundador fue Félix Estrada 
Saladich ${ }^{9}$, propietario de Muebles La Fábrica, que era la empresa que patrocinaba y financiaba la revista. La biografía del fundador de esa compañía, que todavía opera en España, demuestra la capacidad de iniciativa de esa generación de empresarios catalanes de principios del siglo XX, imaginativos e innovadores. Comenzó fundando los famosos Establecimientos Estrada, en la calle Aragó 313 de Barcelona y antes de la guerra era un comercio de comestibles donde el propietario ensayó nuevas formas de venta, como la comercialización de productos ya pesados en las básculas (lo que evitaba pérdidas de tiempo), la presentación con uniforme de los empleados, la adquisición de grandes remesas de productos envasados que le permitía abaratar el precio, la renovación constante de escaparates, la importancia que se concedía a la rotulación y cambio de cartelería, el regalo de dietarios a los clientes o la creación de semanas promocionados como la muy conocida "Siete semanas de la conserva"10. Desde el sector de alimentación fundó en 1942 Muebles La Fábrica, primero en la calle Radas y posteriormente en la calle Rocafort, para cuya inauguración se instaló un castillo de fuegos artificiales para que toda Barcelona supiese dónde se encontraba el nuevo establecimiento. Tiempo después, el 30 de noviembre de 1964, se inauguraría en esa misma calle la sede definitiva de la propia revista, en un moderno edificio de diez plantas y para 1969 comenzaría a operar la gran fábrica de la Zona Franca, destinada a mueble de exportación (La Vanguardia, 1969: 14). Muebles La Fábrica y el grupo Juvalia acabarían creando "La ciudad del Mueble" que fue el complejo industrial de producción mobilaria "más importante de Europa" (Destino, mayo 1964: 12).

La intención de este proyecto editorial liderado por una empresa dedicada a la fabricación de muebles era doble. Por una parte, pretendía "dar prestigio a las empresas del grupo" y, por otra, contribuir a un nuevo concepto de "bienestar y comodidad" (La Vanguardia, 1963: 15) (de hecho el subtítulo de la publicación era "revista de la comodidad"), que coincidía con el tipo de mueble moderno en el que la firma estaba especializada. El éxito de la revista desbordó incluso las previsiones más optimistas de sus patrocinadores. Comenzó con una tirada de 34,000 ejemplares y en junio de 1963 alcanzó los 103,000, con ediciones mensuales y regulares (La Vanguardia, 3 ene. 1963: 33).

El elenco de redactores, ilustradores y decoradores de la revista era realmente heterogéneo. La mayoría de las personas vinculadas en un primer momento eran trabajadores de Muebles La Fábrica, como los proyectistas decoradores hermanos Borau Sado, Batllés Collado, Cercos, Piriz, el valenciano Santisteban o Esteller. Uno de los asesores de los primeros pasos de la revista era Joaquín Bosch Tataret, que sería en 1967 el director de la galería de arte Mundi-Art, otra pieza del complejo entramado de negocios de la familia Estrada, y que se ubicaba en los bajos de la sede de la compañía Muebles La Fábrica, en la calle Rocafort, 142. Como ilustrador trabajó Joaquim Muntañola i Puig en 1961 y progresivamente se introducirán secciones lideradas por mujeres que aportarán sus interpretaciones del hogar moderno.

La revista fue pionera en mostrar casas reales, habitadas por familias, 0 al menos se publicitaban como si así fuesen, aunque es un hecho que en su primera etapa, probablemente por dificultades técnicas, muchas fotografías de conjuntos de mobiliario se hacian en un estudio habilitado a tal efecto. A partir de 1967 uno de los temas recurrentes de la publicación fue el análisis de las posibilidades decorativas y funcionales de lo que se llamaban "mini-pisos", pequeños apartamentos para parejas recién casadas o con un solo hijo, que abundaban en los nuevos barrios residenciales pues el español medio era 
entonces más partidario de la propiedad que del alquiler, y se prefería comenzar la vida familiar en un lugar de pequeñas dimensiones antes que rentar un piso más holgado. En todos los artículos destinados a este segmento del público la revista insiste en lo "felices que viven en un piso pequeñísimo" porque gracias a un buen proyecto de organización del espacio y de la decoración, se conseguían resultados "de película" (La Vanguardia, 8 oct. 1967: 6).

La revista El Mueble comenzó publicando a través de su propia editorial Quiris F.E.M., propiedad de la familia Estrada, pero a finales de la década de los sesenta ya se imprimía en los talleres de La Vanguardia en Barcelona. En esos años, se editaron algunos libros que seguían vinculados la editorial Quiris que se gestó con una orientación exclusivamente empresarial, bajo el paraguas de "Biblioteca de la revista El Mueble". Los títulos estaban dirigidos a un público femenino y abarcaban desde temas de cocina y economía doméstica hasta asuntos relacionados con la educación ${ }^{11}$. Nuevamente se trataba de una estrategia comercial del grupo para promocionar la revista, y paralelamente los muebles de la compañía. En la misma línea de divulgación de la publicación y, por extensión de las producciones de Muebles La Fábrica, se organizarían sorteos periódicos de mobiliarios entre los lectores y suscriptores que eran inevitablemente muebles producidos en las fábricas barcelonesas, o bien originales concursos como el de "Miss Mueble".

Los mensajes publicitarios de difusión de la publicación son elocuentes de las pretensiones de la revista. Se subraya continuamente el concepto de comodidad, confort y bienestar en el hogar, que supondrían "nuevas formas de vivir". Cuando se reitera este mensaje hay que tener en cuenta que el momento de publicación de El Mueble supone el cénit de las migraciones internas en el país, momento en el que miles de españoles abandonaron el campo y se trasladaron a las ciudades. Es decir, las familias pasan de un hábitat rural, con viviendas tradicionales de amueblamiento básico, a un entorno de viviendas colectivas, de apartamentos urbanos donde habrá un sentido racional del espacio y unos conceptos de comodidad y uso distintos. Otro de los puntos relevantes de la estrategia de marketing de la revista en sus primeros momentos fue dirigirse a los novios o recién casados con el sugerente slogan de "La revista que compran todos los novios de España para preparar su futuro hogar".

Otro de los medios de difusión para la divulgación de las propuestas decorativas de Muebles La Fábrica fue el uso de los programas de radio, que fue el gran medio de comunicación de masas en la primera etapa del franquismo. Desde 1945 van a estar presentes los miércoles por la mañana en Radio Barcelona donde, previa aceptación de la censura, se organizaba un programa titulado Carnet de arte en el que se trataban temas relacionados con la música, las artes visuales y la decoración y donde en muchas ocasiones se establecían diálogos entre los locutores (generalmente un hombre y una mujer).

Desde finales de 1966 la revista El Mueble incluirá especiales dedicados a La Cocina, con recetas y menús, que se incluirán en el mismo volumen y paralelamente se mantenían secciones dedicadas a la belleza con el respaldo de la correspondiente publicidad de empresas cosméticas. La revista se convertía entonces en una publicación totalmente feminizada, hasta que en 1969 se decidió seccionar los intereses heterogéneos de la publicación, creando la revista Belleza y Moda. A partir de entonces El Mueble regresaría a sus intereses iniciales de decoración e interiorismo. 
A diferencia de otras revistas anteriores, El Mueble tuvo desde sus orígenes una decidida vocación internacional. Estuvo presente en la Feria Mundial de Nueva York ${ }^{12}$ o en la de Colonia de 1966, con invitación expresa de la organización. Esa voluntad de internacionalización se ratifica incluso si comprobamos las ofertas de empleo publicadas en la prensa de Barcelona, donde insistentemente de buscan mecanógrafas con conocimientos de alemán e inglés para el Departamento Extranjero de la redacción (La Vanguardia, 12 feb. 1976: 81) ${ }^{13}$.

En el contenido de la revista, se insistía continuamente en la sencillez moderna y en raras ocasiones se hacen repasos históricos como los que eran habituales en Arte y Hogar. El color se introduce paulatinamente, primero sólo reducido a las portadas para pasar a ser enteramente coloreada hacia 1975. En cuanto a la publicidad, está abundaba en página completa y media página, con un especial y por otra parte lógico énfasis en las industrias del grupo La Fábrica. Además de productos nacionales, aparecerán producciones extranjeras y firmas foráneas, lo que ratifica la apertura exterior del Régimen a las importaciones. Igualmente se van a reproducir soluciones decorativas del ámbito alemán, inglés, francés y norteamericano, dando incluso cabida a propuestas de decoradores de estas procedencias. Incluso en los reportajes o anuncios de decoraciones nacionales, se insiste en que pertenecen a un estilo "europeo" o que están influidos por lo extranjero, algo impensable en fechas anteriores.

Los contenidos de El Mueble eran similares a los de las actuales revistas de decoración. Había monográficos dedicados a diferentes estancias del hogar, secciones especializadas en mueble actual e innovaciones del diseño, consultorios, repasos de las ferias nacionales y extranjeras, singularmente la Feria de Valencia y las novedades de la cita anual Hogarotel que se celebraba en Barcelona desde 1961 como heredero de la anterior muestra de los cincuenta El hogar moderno.

\section{Otras revistas de decoración de finales de la década de los sesenta}

Después del éxito de la revista El Mueble, van a aparecer otras revistas como Hogares Modernos [fig. 3], en junio de 1966, que llevaba el sugerente subtítulo: La revista de la decoración, el mueble y la arquitectura. Es una publicación que continúa también en la actualidad con el título más reducido de Hogares, y que como en el caso anterior, se editó desde Barcelona. En los primeros pasos de la revista, el jefe de redacción era el novelista Manuel Vázquez Montalbán, quien en 1969 publicaría una divertida sección en la publicación titulada "Las andanzas de Jack el decorador", donde por primera vez el escritor utilizaba un seudónimo y se identifica con una especie de detective ${ }^{14}$ que critica al propio mobiliario de la revista, el culto moderno a las modas, las muestras que se celebraban en Barcelona bajo el nombre de Hogarotel, o la decoración modernísima de la discoteca en la ciudad condal. La sección, a pesar de las críticas que despertaba entre los más de 48.000 lectores y entre los propios anunciantes, se mantuvo (al final de manera intermitente) hasta 1972. En muchos de los artículos de Vázquez Montalbán se obviarán los temas relacionados con el interiorismo para abordar otros temas culturales más acordes con los intereses del escritor. Así en "La casa de Don Pío Baroja" - publicado en junio de 1969 - no se habla de la casa ni de su decoración, sino de que se ofrece un recorrido literario por la obra del vasco. El planteamiento de Hogares Modernos era, valga la redundancia, mucho más moderno que El Mueble. Las fotografía tenían mucha más calidad, había más diseño en la maquetación y primaba la imagen sobre el texto. 


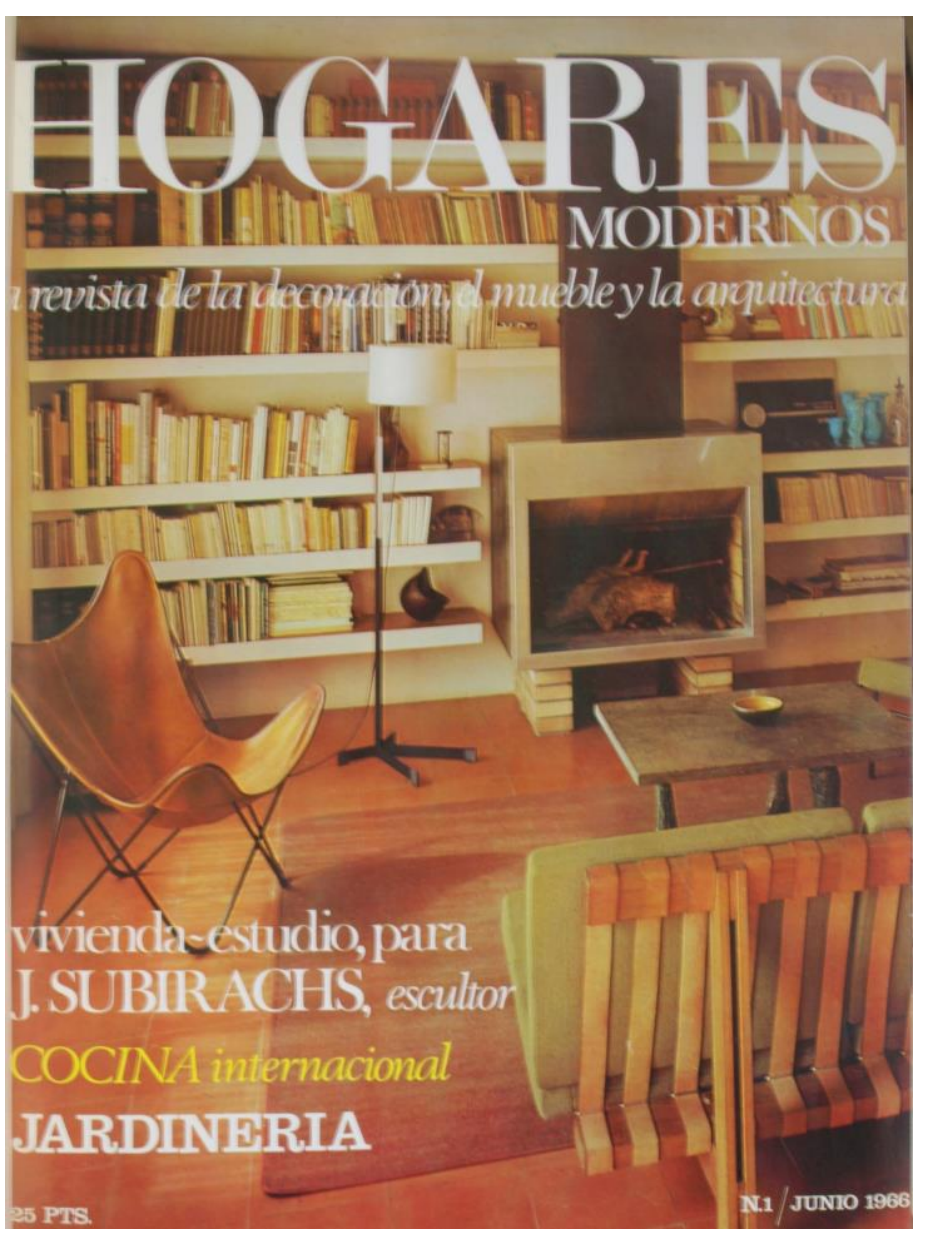

Fig. 3. La revista Hogares Modernos. Arquivo da autora.

Este breve recorrido por las principales revistas de decoración durante el franquismo atestigua los modos de consumo doméstico en España en los dos periodos del Régimen. En un primer momento (el de la autarquía), estaríamos ante revistas amparadas en la cultura propiciada por el fascismo, controlada ideológicamente, mientras que en el segundo periodo la apertura de la dictadura se dejará sentir en nuevas formas de entender los interiores domésticos, más modernos, prácticos y funcionales. Las estrategias editoriales están vinculadas a iniciativas empresariales, cuentan con un mayor contenido publicitario y se gestan a imitación de modelos modernos europeos.

\section{Referências}

ARNAUD IMATZ, José Antonio. Falange

ASTORGA, Mónica Vázquez. Los monumentos Española y el Nacionalsindicalismo. Madrid: a los caídos: ¿un patrimonio para la memoria 0 
para el olvido? Anales de Historia del Arte, n. 16, p. 285-314, 2006.

AZNAR ROSALES, Juan. Un tal Juan (que no fue rey). Barcelona, 1998. Disponible en: <http://memoriapopular.org/obres/1-1/1-1.pdf>. Acesso en: 16 dic. 2013.

DESTINO, Barcelona: mayo 1964.

DÍAZ SÁNCHEZ, Julián y LLORENTE, Ángel. La crítica de arte en España (1939-1976). Madrid: Akal, 2004.

JIMÉNEZ, José Luis Rodríguez. Historia de Falange Española de las JONS. Madrid: Alianza, 2000.

LA VANGUARDIA. Barcelona, 3 ene. 1963.

Barcelona: 12 feb., 1967.

Barcelona, 8 oct. 1967.

Barcelona, 14 mar. 1969.

LÓPEZ DÍAZ, Jesús. Vivienda Social y Falange: ideario y construcciones de la década de los 40 . Scripta Nova, vol. VII, n. 146, 2003.

MUÑOZ RUIZ, María del Carmen. Las revistas para mujeres durante el franquismo: difusión de modelos de comportamiento femeninos. Mujeres y hombres en la España franquista: sociedad, economía, política y cultura, editado por Gloria Nielfa Cristóbal. Madrid: Editorial Complutense, 2003, p. 95-114.

PRESENTACIÓN. Arte y Hogar, n. 1, p. 6, 1943.

RODRÍGUEZ JIMÉNEZ, José Luis. Historia de Falange Española de las JONS. Madrid: Alianza, 2000.

ROSALES, Juan Aznar. Un tal Juan (que no fue rey). Barcelona, 1998. Disponible en: <http://memoriapopular.org/obres/1-1/1-1.pdf>. Acesso en: 16 dic. 2013.

SOLÁ-MORALES, Ignasi. La arquitectura de la vivienda en los años de la autarquía (19391953)". Arquitectura, n. 99, 1976.

SOTO, Emilio Sanz de. Vitín Cortezo: un personaje. El País, $\mathrm{X}$ (suplemento), 19 mar. 1978.

VÁZQUEZ ASTORGA, Mónica. Los monumentos a los caídos: ¿un patrimonio para la memoria o para el olvido? Anales de Historia del Arte, 16, p. 285-314, 2006.

VÁZQUEZ MONTALBÁN, Manuel (Jack el decorador). De cómo nació y creció Jack el Decorador. Hogares modernos, Barcelona, marzo 1969.

\section{Notas}

\footnotetext{
* Profesora Titular de Historia del Arte de la Universidad de Oviedo, investigadora principal de proyectos nacionales e internacionales, comisaria de exposiciones y directora del departamento de Historia del Arte y musicologia. E-mail: afgarcia@uniovi.es.

${ }^{1}$ Baste señalar que el nivel económico del país en 1956 era similar al de 1936, justo antes de la contienda civil. N. de la A.

2 Falange Española fue un partido político de ideología nacional sindicalista, fundado el 29 de octubre de 1933 por José Antonio Primo de Rivera. A los pocos meses de su creación se fusionaría con las JONS (Juntas de Ofensiva Nacional-Sindicalista, liderada por Onésimo redondo y Ramiro Ledesma. Jugó un papel importante en los sucesos que condujeron a la Guerra Civil y tuvo evidentes paralelismos con el Fascio italiano, no sólo a nivel ideológico sino también en su indumentaria, gestos (saludo romano) y símbolos (Arnaud Imatz, 2003).

${ }^{3}$ La OSH fue una iniciativa nacida en la Falange (a imitación de proyectos fascistas italianos) para proporcionar vivienda a los "productores" adelantando el Instituto Nacional de la Vivienda en $90 \%$ del coste de la casa, dinero que se iría devolviendo en mensualidades durante 40 años. La OSH fue a la vez promotora y constructora de decenas de grupos de viviendas que, frente a la hegemonía del "estilo imperial" de los primeros años del franquismo, ofrecía propuestas racionalistas, herederas de las anteriores del GATEPAC (Jiménez, 2000)(Solá-Moales, 1976)(López Díaz, 2003). Eduardo Olasagasti editaría en 1958 el libro Una casa en cada paisaje, que venía a ser un compendio de los artículos publicados en Arte y hogar, y en 1961 el texto Piscinas, ambos editados por Cigüeña, la misma editorial que la revista.

${ }^{4}$ Viladomat Pancorbo ilustró junto a Carlos Sáenz de Tejada las dos principales obras que interpretaban la guerra civil: Historia de la Cruzada Española y Laureados de España, 1936-1939. En esa última obra, que vio la luz en 1939, la dirección de la edición y de la faceta artística correspondió respectivamente a Fermina de Bonilla (quien será después editora de Arte y Hogar) y a Viladomat.
} 
${ }^{5}$ Su primera experiencia cinematográfica fue el documental Hombres Ibéricos (1946) pero llegaría a hacer catorce películas - Cerca del cielo (1951), Hermano menor (1952), Llegaron siete muchachas (1957), Gayarre (1958), Perro golfo (1961) - siendo galardonado con el Premio Nacional de Cinematografía.

${ }^{6}$ Rodríguez Filloy se convertiría en el crítico del diario falangista Arriba en 1943, desde el fallecimiento de Manuel Abril (Díaz Sanchez; Llorente, 2004: 139).

${ }^{7}$ Conviene recordar que durante las primeras décadas del franquismo sólo podrían trabajar (de acuerdo con el Fuero del trabajo promulgado en 1938) las mujeres solteras o viudas. N. de la A.

${ }^{8}$ En Valencia había participado en el II Congreso de la Alianza de Escritores Antifascistas en Valencia en 1937 donde hizo su primer montaje teatral para Mariana Pineda de Lorza, dirigida por Manuel Altolaguirre (Soto, 1978: suplemento).

${ }^{9}$ Además de actividad empresarial, Félix Estrada Saladich escribió varios libros como El comercio detallista, El despacho y su organización, Cómo se forma un vendedor, La publicidad en España o las Memorias de un comerciante catalán. En 1954 creó la Biblioteca de Iniciativas comerciales. Fue además coleccionista de arte en la década de los sesenta y adquirió obras de pintores como Ramón Calsina, Rocío Ahnert, y casi un centenar de esculturas con la idea de crear un museo propio. Gran parte de esa colección se encuentra la Finca El Pedregar, que pertenece a la Fundación Estrada Saladrich. Su pasión por el arte se encauzó también a través de la Bienal Internacional F. Estrada Saladich a finales de los sesenta.

${ }^{10}$ Esta información está recogida en el texto autobiográfico de Juan Aznar Rosales (1998).

${ }^{11}$ El listado de obras editadas por Quiris en la biblioteca El Mueble (denominada como "La biblioteca de la felicidad") puede resumirse en algunos títulos muy elocuentes de la orientación y destinatarias de los textos: El secreto de las mesas bien puestas (1965), Adelgazar comienza con una manzana (1965), El libro de los sándwiches (1965), Bordar es cosa fácil (1969), Gran libro de la gimnasia (1969), Cómo ahorrar en casa (1969) o Cómo educar a los hijos (1969).

12 Y el propio Estrada Saladich publicaría un libro sobre esta experiencia en 1965. N. de la A.

${ }^{13}$ La revista El Mueble tuvo a fines de los sesenta una edición especial en México, con el mismo contenido que la española pero con anunciantes de México.

${ }^{14}$ Se autodenominaba como miembro del cuerpo de agentes secretos en defensa de los objetos inertes, ascendiendo posteriormente a "Inspector Especial de la Decoración Europea" (Váquez Montalbán, 1969).

Artigo recebido em janeiro de 2018. Aprovado em abril de 2018. 